\title{
Effect of body mass index on pulmonary function tests among diabetic patients in Manipur
}

\author{
Sunetra Sarma ${ }^{1, *}$, L. Suresh Roy ${ }^{2}$, Prakash Chandra Bhardwaj ${ }^{3}$, Tyngshainlang Sutnga ${ }^{4}$ \\ ${ }^{1,3,4}$ Post Graduate Trainee, ${ }^{2}$ Professor, Dept. of Physiology, Regional Institute of Medical Sciences (RIMS), \\ Imphal, Manipur, India
}

*Corresponding Author:

Email: sunetra.brate@gmail.com

\begin{abstract}
Introduction: Diabetes mellitus (DM) is an important public health problem, where patients do not present with any pulmonary complaints because of large vascular and ventilatory reserve. As obesity is regarded as one of the risk factors leading to diabetes, the present study will try to determine the effect of body mass index (BMI) on pulmonary system.

Aim: The present study is aimed to find out the effect of BMI on pulmonary function tests (PFTs) among diabetic patients.

Materials and Methods: The study was undertaken in the departments of Physiology and Medicine to determine the effect of BMI on PFTs. Thirty (30) known diabetic patients were recruited from medicine OPD on the basis of guidelines according to American Diabetes Association (ADA) and they were divided into two groups based on their BMI. PFTs were performed using computerized spirometer. Data were entered and analyzed using independent student's t-test.

Results: Patients with higher BMI have reduced values of Forced Vital Capacity (FVC), Forced Expiratory Volume in 1st sec (FEV1), FEV1/FVC, Forced Expiratory Flow in between 25\%-75\% (FEF25-75\%) compared to those with lower BMI, whereas with higher BMI, Peak Expiratory Flow Rate (PEFR) was increased. The differences in FEV1, PEFR and FEF25\%-75\% values among the two groups were found to be significant (pvalues are $0.003,0.05$ and 0.026 respectively).

Conclusion: Increased BMI can have detrimental effects on pulmonary functions among diabetics. So, early awareness about body weight and prevention strategy would be important steps towards making a diabetes free nation.
\end{abstract}

Keywords: Body Mass Index (BMI), Diabetes Mellitus, Pulmonary Function Tests (PFTs).

Received: $14^{\text {th }}$ December, 2017

Accepted: $19^{\text {th }}$ December, 2017

\section{Introduction}

Diabetes mellitus (DM) is an important public health problem with about 347 million people being diagnosed to have diabetes with a global average prevalence of approximately $10 \%$, according to World Health Organization (WHO). India is referred to as the diabetes capital of the world and estimation says that by 2025 , there will be nearly 70 million people with diabetes in India, which means every $5^{\text {th }}$ diabetic in the world would be an Indian. ${ }^{1}$

Usually diabetic patients do not present with any pulmonary complaints because of its large vascular and ventilatory reserve, which is the reason behind the poor understanding of pulmonary complications of diabetes. But abnormal phagocytic actions induced by hyper glycaemia and the impact of non-enzymatic glycation of the lung rich in collagen and elastin may lead to stiffening of the thorax and lung parenchyma are some of the reasons given for lung involvement in diabetic process. ${ }^{2}$
Obesity is always regarded as an important risk factor for metabolic syndromes including diabetes. As higher body weight is associated with hypertriglyceridemia, this might play a role in the pathogenesis of decreased lung functions in diabetic patients. ${ }^{3}$ Abdominal obesity was strongly associated with lung function impairment, independently of major risk factors. ${ }^{4}$ Obesity also causes reduction in pulmonary function parameters like $\mathrm{FEV}_{1} / \mathrm{FVC}$ at all ages while FVC and Maximum Mid Expiratory Flow( MMEF) were negatively associated with body mass index(BMI). ${ }^{5}$ So the aim of this study is to find out the effect of BMI on pulmonary function tests (PFT) parameters in diabetic patients.

\section{Material and Methods}

It was a cross-sectional study, which was conducted in the Departments of Physiology and Medicine, RIMS, Imphal during the period of 5(five) months (July, 2016 to November, 2016). Thirty (30) known diabetic patients were recruited for the study, 
who were selected on the basis of guidelines according to American Diabetes Association (ADA). The patients were divided into two groups: group-I with BMI 18- 24.9 and group II where BMI was above 25 . The height and weight were measured and BMI calculated. Pulmonary Function Tests (FVC, $\mathrm{FEV}_{1}, \mathrm{FEV}_{1} / \mathrm{FVC}, \mathrm{PEFR}$ and $\mathrm{FEF}_{25-75 \%}$ ) were recorded using Computerized Spirometer (Helios 702, RMS, Chandigarh). Ethical approval was taken from Research Ethics Board, RIMS, Imphal. Data were collected and entered in SPSS (Statistical Package for the Social Sciences, version 21) and the association of two groups were analyzed using independent student's t-test.

\section{Results and Discussion}

The study evaluated various pulmonary functions among diabetic patients which are FVC, $\mathrm{FEV}_{1}, \mathrm{FEV}_{1} / \mathrm{FVC}, \mathrm{PEFR}$ and FEF $25-75 \%$.

The results of the two groups were obtained and compared. Out of 30(thirty) diabetic cases, 21(twenty one), belonged to group I and 9(nine), to group II. The mean age of group I and group II patients were $56.85 \pm 11.8$ yrs and $50.11 \pm 8$.1yrs respectively as shown in table I.

Table I: Mean age of the groups

\begin{tabular}{|l|c|c|}
\hline \multicolumn{1}{|c|}{ Group } & Number(n) & Age(yrs) \\
\hline I & 21 & $56.85 \pm 11.8$ \\
\hline II & 9 & $50.11 \pm 8.1$ \\
\hline
\end{tabular}

Table II showed that few lung parameters (FVC, $\mathrm{FEV}_{1}, \mathrm{FEV}_{1} / \mathrm{FVC} \& \mathrm{FEF} 25 \%-75 \%$ ) were decreased among group II patients in comparison with group I patients, but PEFR values were increased among group II patients. It was found that only $\mathrm{FEV}_{1}, \mathrm{PEFR}$ and $\mathrm{FEF}_{25 \%-75 \%}$ values were significantly associated with increased BMI.

Table II: PFT values among the patients

\begin{tabular}{|l|c|c|}
\hline Parameters & Group I & Group II \\
\hline FVC(L) & $2.7510 \pm 0.68$ & $2.6544 \pm 0.75$ \\
\hline $\mathrm{FEV}_{1}(\mathrm{~L})$ & $2.2548 \pm 0.18^{*}$ & $1.7044 \pm 0.72^{*}$ \\
\hline $\mathrm{FEV}_{1} / \mathrm{FVC}$ & $69.6610 \pm 9.69$ & $66.0722 \pm 23.24$ \\
\hline $\mathrm{PEFR}_{(\mathrm{L} / \mathrm{S})}$ & $3.4287 \pm 0.90^{*}$ & $4.5933 \pm 2.38^{*}$ \\
\hline $\mathrm{FEF}_{25 \%-75 \%}$ & $3.1195 \pm 0.72 *$ & $2.3611 \pm 0.98^{*}$ \\
\hline
\end{tabular}

Study by Adeyeye $\mathrm{OO}$ et $\mathrm{al}^{2}$ showed no significant association of BMI with PEFR (3.70+0.98, $\mathrm{p}=0.00)$ and $\operatorname{FEV}_{1}(1.61 \pm 0.62$, $\mathrm{p}=0 . \overline{00})$. However a negative association were found between BMI and FVC (2.03 \pm 0.76 , $\mathrm{p}=0.00$ ). In contrast, the present study showed significant association between BMI with PEFR and $\mathrm{FEV}_{1}$, but no such association between BMI and FVC.

A study done by Klein OL et $\mathrm{al}^{6}$ have found significant reduction in $\mathrm{FEV}_{1}(75.3 \pm 0.7 \%$ of predicted) and FVC $(71.2 \pm 0.7 \%$ of predicted $)$ among high BMI diabetics, where the present study have these values as $1.7044 \pm 0.72$ and $2.6544 \pm 0.75$ respectively in high BMI group-II, which is quite low when compared to lower BMI group-I $(2.2548 \pm 0.18$ and $2.7510 \pm 0.68$ respectively)

Again, Özmen B et $\mathrm{al}^{7}$ found gradual diminution of values of $\mathrm{FEV}_{1}$ among three groups of BMI in which the values were $105 \pm 10.59 \%, 100.33 \pm 7.23 \%$ and $96.50 \pm 17.09 \%$ of the predicted values respectively for BMI groups of $<25,25-26.9$ and $>27$. But in cases of $\mathrm{FVC}$ and $\mathrm{FEF}_{25 \%-75 \% \text {, there were variations }}$ among the different groups. FVC was maximum (96.67 $\pm 10.50 \%$ of predicted) among patients of BMI 25-26.9 in comparison to FVC values of $92.89 \pm 10.43 \%$ and $91.39 \pm 14.65 \%$ of predicted among patients of BMI $<25$ and $>27$ groups respectively. Again $\mathrm{FEF}_{25 \%-75 \%}$ value was maximum (110.44 $\pm 31.16 \%$ of predicted) among patients of BMI <25 in comparison to values of $85.67 \pm 15.89 \%$ and $89.28 \pm 39.79 \%$ of predicted among BMI groups 25-26.9 and >27 respectively. But these values were within normal limits and showed no significant association, whereas the present study showed decreasing values of these three parameters with increasing BMI and the differences were significant.

According to Rao UR et $\mathrm{al}^{8}$, reduced values of FVC were found to be associated with increasing BMI, but higher values of $\mathrm{FEV}_{1}$ and $\mathrm{FEV}_{1} / \mathrm{FVC}$ were associated with increasing BMI, whereas the present study showed that all the parameters (FVC, $\mathrm{FEV}_{1}$ and $\mathrm{FEV}_{1} / \mathrm{FVC}$ ) were kept on decreasing with increased BMI.

S Karande et al, ${ }^{9}$ Panesar $\mathrm{P}$ et al, ${ }^{10}$ Kaur $\mathrm{S}$ et $\mathrm{al}^{11}$ and Mane SB et al ${ }^{12}$ also found significant reduction in values of all PFT parameters with raised BMI. But contrary to these studies, the present study showed similar findings except for PEFR which was found to be increased with increasing BMI. On the other hand, studies by Gajbhiye RN et al, ${ }^{13}$ Acharya $\mathrm{P}$ et $\mathrm{al}^{1}$ and Latha $\mathrm{S}$ et $\mathrm{al}^{5}$ did not find any correlation between BMI and PFTs which are against the finding of the present study.

The relevance of decrease in $\mathrm{FEV}_{1}$ and increase in PEFR with increase in BMI among the diabetic patients need to be examined in the context of normal physiological functions of lungs. So, perhaps increased BMI might have detrimental effects on the pulmonary functions. 


\section{Conclusion}

Increased BMI seem to have detrimental effects on pulmonary functions among diabetics. So, the need of the hour will be early awareness about body weight management and prevention strategy which would be the important steps towards making a diabetes free nation.

\section{References}

1. Acharya PR, D Souza M, Anand R, Kotian SM,“ Pulmonary Function in Type 2 Diabetes Mellitus: Correlation with Body Mass Index and Glycemic Control" International Journal of Scientific Study (2016) 3,18-23.

2. Adeyeye OO, Ogbera OA, Dada AO, Bamisile RT, Brodie Mens A, "Correlates of Abnormal Pulmonary Function Tests in Persons with Type 2 Diabetes Mellitus" Journal of Pulmonary \& Respiratory Medicine (2014) 5, 231.

3. Irfan M, Jabbar A, Haque AS, Awan S, Hussain SF, "Pulmonary functions in patients with diabetes mellitus" Lung India (2011) 28, 89-92.

4. Leone N, Courbon D, Thomas F, Bean K, Jégo B, Leynaert B, Guize L, Zureik M, "Lung function impairment and metabolic syndrome: the critical role of abdominal obesity" American Journal of Respiratory and Critical Care Medicine (2009) 179, 509-16.

5. Latha S, Andrew RS, Shaymala R, Brinda S, "Influence of BMI in Pulmonary Function Test in Diabetic Subjects" Journal of Medical Science \& Clinical Research (2015) 3, 4233-40.

6. Klein OL, Meltzer D, Carnethon M, Krishnan JA, "Type II diabetes mellitus is associated with decreased measures of lung function in a clinical setting" Respiratory Medicine (2011) 105, 1095-98.

7. Özmen B, Celik P, Yorgancioğlu A, Özmen B, Özmen D, Cok G, "Pulmonary function parameters in patients with diabetes mellitus" Diabetes Research and Clinical Practice (2002) 57, 209-11.

8. Rao UR, Amaravathi KS, Abhilash T, "A Study on Pulmonary Function Tests in Metabolic Syndrome" Indian Journal of Applied Research (2017) 6, 267-70.

9. Karande S, Pednekar SJ, Nabar ST, Mehta A, Iyengar V, " Pulmonary functions in type 2 diabetes mellitus patients: an observational study at a tertiary level hospital in Mumbai, Maharashtra, India" International Journal of Research in Medical Sciences (2016) 4, 1574-7.

10. Panesar P, Nayyar SB, Mohan G, Sareen BC, "Spirometric Evaluation Of Pulmonary Function In Patients With Type 2 Diabetes Mellitus (T2DM)" International Journal of Advanced Research (2016) 4, 1451-58.

11. Kaur S, Agarwal N, "Pulmonary function tests in type 2 diabetes mellitus" Archives of Medicine and Health Sciences (2016) 4,35-9.

12. Mane SB, Somani SS, Mundkar SM, Shinde MS, "The Study of Pulmonary Functions in Patient of Type 2 Diabetes Mellitus" Journal of Evidence Based Medicine and Healthcare (2016) 3, 438082.
13. Gajbhiye RN, Tambe AS, "Pulmonary function test in type 1 diabetics" Global Journal of Biology, Agriculture \& Health Sciences (2014) 3,20-2. 